Çukurova Üniversitesi Mühendislik Mimarlık Fakültesi Dergisi, 34(3), ss. 21-34, Eylül 2019

Çukurova University Journal of the Faculty of Engineering and Architecture, 34(3), pp. 21-34, September 2019

\title{
Sıkıştırma ile Ateşlemeli Bir Motora Hidrojen İlavesinin Egzoz Emisyonlarına Etkisi
}

\author{
Mehmet AKÇAY ${ }^{*}$, İlker Turgut YILMAZ², Ahmet FEYZİOĞLU², Salih ÖZER \\ ${ }^{1}$ Muş Alpaslan Üniversitesi, Mühendislik Mimarlık Fakültesi, Makine Mühendisliği Bölümü, \\ Muş \\ ${ }^{2}$ Marmara Üniversitesi, Teknoloji Fakültesi, Makine Mühendisliği Bölümü, İstanbul
}

Geliş tarihi: 17.01.2019 Kabul tarihi: 30.09 .2019

\section{$\ddot{\mathbf{O z}}$}

Bu çalışmada, hidrojen miktarının hidrojen-dizel yakıtlı sıkıştırma ile ateşlemeli (CI) motorun üzerindeki etkisi araştırılmıştır. Hidrojen, sürekli olarak bir karıştırma odasına gönderilmiştir. Dizel yakıt, Common Rail yakıt enjeksiyon sistemi ile silindirlere gönderilmiştir. Deneysel çalışmada; dört silindirli, dört zamanlı, su soğutmalı, 1,461-L ve turbo şarjlı CI motoru kullanılmıştır. Egzoz emisyonları, 1750 d/d sabit hızda $40 \mathrm{Nm}, 60 \mathrm{Nm}$ ve $80 \mathrm{Nm}$ motor yükleri altında incelenmiştir. Hidrojen debileri; 10 1/d, 20 1/d ve 30 l/d olarak seçilmiş ve $\mathrm{H} 10, \mathrm{H} 20$ ve $\mathrm{H} 30$ olarak isimlendirilmiştir. Sonuçlara göre, $\mathrm{NO}_{\mathrm{x}}$ ve $\mathrm{CO}_{2}$ emisyonlarında iyileşmeler olurken, $\mathrm{HC}$ ve is emisyonları artış meydana gelmiştir. Hidrojen katkısının $\mathrm{O}_{2}$ emisyonu üzerine etkisinin oldukça düşük olduğu görülmüştür.

Anahtar Kelimeler: Sıkıştırma ile ateşlemeli motor, Hidrojen, Egzoz emisyonları

\section{Effect of Hydrogen Addition on Exhaust Emissions in a Compression Ignition Engine}

\begin{abstract}
In this paper, a research on effect of hydrogen amount on hydrogen-diesel fuelled compression ignition (CI) engine was conducted. Hydrogen was continuously inducted into a mixing chamber. Diesel fuel was sent into cylinders by Common Rail fuel injection system. A four-cylinder, four-stroke, water cooled, 1.461-L and turbocharged CI engine was used for test. Exhaust emissions were investigated under $40 \mathrm{Nm}$, $60 \mathrm{Nm}$ and $80 \mathrm{Nm}$ engine loads at constant speed of $1750 \mathrm{rpm}$. Hydrogen flow rates were chosen as $10 \mathrm{lpm}$, $20 \mathrm{lpm}$ and $30 \mathrm{lpm}$ and called as $\mathrm{H} 10, \mathrm{H} 20$ and $\mathrm{H} 30$. According to the results, improvements in $\mathrm{NO}_{\mathrm{x}}$ and $\mathrm{CO}_{2}$ emissions were observed, while $\mathrm{HC}$ and smoke emissions increased. The effect of hydrogen addition on $\mathrm{O}_{2}$ emissions was found to be quite low levels.
\end{abstract}

Keywords: Compression ignition engine, Hydrogen, Exhaust emisisons

*Sorumlu yazar (Corresponding author): Mehmet AKÇAY, mehmetakcay@yahoo.com 


\section{GíRiș}

Nüfus artışı ile birlikte her geçen gün enerji ihtiyacı da artmakta, artan bu enerji ihtiyacının büyük bir kısmı sınırlı ömrü olan petrol, kömür ve doğalgaz gibi fosil yakıtlar tarafından sağlanmaktadır. Fosil yakıtların kullanılması hava kirliliğine ve ormanlara zarar veren asit yağmurlarına neden olmanın yanı sıra, karbondioksit (sera gazı etkisi) birikmesine ve dolayısıyla da yeryüzünün sıcaklık dengesinin değişmesine yol açmaktadır [1,2].

Fosil kökenli yakıtların yanması ile açığa çıkan hidrokarbon, karbon monoksit ve azot oksit emisyonlarının yarısının buji ve sıkıştırma ile ateşlemeli motorlardan kaynaklandığı ifade edilmektedir [3]. Fosil yakitların temiz ve yenilenebilir enerji kaynağı ile değiştirilmesi, otomotiv endüstrisini, enerji kıtlığı ve çevre kirliliğinden kaynaklanan tasarım baskılarından kurtarmak için etkili bir yöntemdir [4]. Son zamanlarda içten yanmalı motorlarda (IYM) daha az zararlı emisyon salgılayan alternatif enerji kaynakları ile ilgili yapılan çalışmalar incelendiğinde, genel olarak biyodizel $[5,6]$, alkoller [7,8], sıkıştırılmış ve sıvılaştırılmış doğal gaz [9-11], sıvılaştırılmış petrol gazı $[12,13]$ ve hidrojen [14-16] gibi enerji kaynaklarına odaklanıldığ görülmektedir.

Hidrojen, doğada kendi başına bulunmayan fakat su, fosil yakıtlar ve biyokütle gibi herhangi bir hidrojen içeren kaynaktan sentezlenebilen bir gazdır [17]. Hidrojen, karbon esaslı olmayan, oksijen ile yanması sonucunda yanma ürünü olarak su oluşturan ve çevre dostu olan zehirsiz, kokusuz, yenilenebilir ve geri dönüştürülebilir alternatif bir yakıttır $[3,18,19]$. Hidrojenin yanması sonucunda hidrokarbon ve karbon monoksit gibi zehirli ürünler oluşmadığından dolayı hava kalitesine olumlu katkıda bulunmaktadır [20-22]. Dolayısıyla hidrojen, hızla tükenmekte olan petrol kaynaklarından elde edilen yakıtların yerini alabilecek, hem sıkıştırma ile ateşlemeli hem de buji ile ateşlemeli motorlar için geleceğin alternatif yakıtı olarak görülmektedir $[2,18]$.

Hidrojen, yaygın olarak kullanılan benzin, dizel ve doğal gaz gibi geleneksel fosil yakıtlar ile karşılaştırıldığında; daha yüksek alev yayılma hızı, daha düşük tutuşma enerjisi, daha hızlı difüzyon oranı, daha geniş tutuşabilirlik sınırı ve daha kısa alev sönme mesafesi gibi birçok avantaja sahiptir [4,22-26]. Hidrojen gazının düşük tutuşma enerjisi, geniş tutuşabilirlik aralığı ve yüksek yanma hızı gibi özellikleri IYYM'lerde yanma için yetersiz koşullar altında dahi yakılabilmesini sağlar [27]. Hidrojenin eşdeğerlik oranı 0,1-7,1 arasında değişmektedir ve böylece hidrojen gazı ile çalışan motor geniş bir yakıt/hava oranı sınırları içerisinde çalışabilmektedir. Hidrojenin kütlesel olarak alt ısıl değeri dizel ve benzin yakıtlarının alt isıl değerlerinden çok daha yüksektir [23]. Hidrojenin yüksek difüzyon hızı ve yüksek alev yayılma hızı sayesinde yanma süresini k1saltabilmektedir [24,28,29]. Bu nedenle, hidrojen yakitlı motorun çevrimi ideal sabit hacim çevrimine daha yakındır ve hidrojen kullanımı ile motorun termal verimliliği artırabilmektedir [24].

Hidrojen, dizel ve benzin yakıtlarının başlıca fiziksel özellikleri Çizelge 1'de gösterilmektedir. [14,17,22,30-32]. Çizelge 1'den görüldüğü üzere, diğer yakıtlara göre hidrojenin yüksek difüzyon katsayısı sayesinde hızlı karışım oluşturulabildiğinden, hava ile daha iyi bir karışım oluşturup homojen bir dolgu oluşturulduğu kabul edilebilmektedir. Ayrıca, hidrojenin kendi kendine tutuşma sıcaklığı yüksek [33] olduğundan dolayı, daha yüksek sıkıştırma oranlarında kullanıma imkân sağlamaktadır.

Dizel motorlarına düşük miktarlarda hidrojen katkısı ile yakıtın toplam $\mathrm{H} / \mathrm{C}$ oranı artmakta, hidrojenin yüksek difüzyon katsayısı sayesinde daha homojen bir yakıt-hava karışımı sağlanarak dizel yakı spreyinin heterojenliği azaltılabilmektedir. Hidrojenin alev yayılma hızı yüksek olduğundan dolayı daha yanıcı bir karışım oluşturulabilmektedir $\quad[28,29,34]$. Hidrojenin yüksek alev hızı nedeniyle hidrojen oksidasyonu sırasında çevreye daha az isı transferi gerçekleşmektedir. Hidrojenin alev sönme bölgesi normal hidrokarbon yakıtlara göre yaklaşı 3 kat daha az (Çizelge 1) olduğundan dolayı, hidrojen alevi silindir duvarına daha da yaklaşabilmekte ve yakıtın tamamına yakınının yanması sağlanmaktadır. Bu nedenle hidrojen katkısı ile çift 
yakıtlı hale getirilmiş motor, tek yakıtlı motora göre daha kararlı çalışmaktadır [35]. Hidrojen, bir gaz olduğu için hava ile daha iyi karışabilmekte ve yanma işlemi tam yanma olarak gerçekleşebilmektedir [36].

Çizelge 1. Dizel, benzin ve hidrojenin başlıca fiziksel özelliklerinin karşılaştırılması

\begin{tabular}{|l|c|c|c|}
\multicolumn{1}{|c|}{ Properties } & Dizel & Benzin & Hidrojen \\
\hline Yoğunluk $\left(\mathrm{kg} / \mathrm{m}^{3}\right.$ ) & $833-881$ & 790 & 0,0838 \\
\hline Havada ateşleme sınırı (hacim \%) & $0,7-5$ & $1,0-7,6$ & $4-75$ \\
\hline Ateşleme sıcaklığı (K) & 530 & $501-744$ & 858 \\
\hline Minimum ateşleme enerjisi (MJ) & - & 0,24 & 0,02 \\
\hline Stokiyometrik hava-yakıt oran1 & 14,5 & 1,76 & 34,3 \\
\hline Havada yanıcılık sınırı eşdeğerlik oranı & - & $0,7-3,8$ & $0,1-7,1$ \\
\hline Alt 1sıl değer (MJ/kg) & 42,5 & 44,79 & 119,93 \\
\hline Laminer alev hızı (cm/s) & 30 & $37-47$ & $265-325$ \\
\hline Alev sönme mesafesi (cm) & - & 0,2 & 0,064 \\
\hline Hava içindeki difüzyonu $\left(\mathrm{cm}^{2} / \mathrm{s}\right)$ & 0,038 & 0,05 & 0,63 \\
\hline Oktan sayısı & 30 & 85 & 130 \\
\hline
\end{tabular}

Hidrojen, sahip olduğu üstün özelliklere rağmen, IYM'lerde kullanılması ile ilgili bazı dezavantajları da bulunmaktadır. Hidrojen gazı ile çalışan motor, hidrojenin hacim bazındaki düşük alt 1sıl değerinden dolayı daha düşük güç üretmektedir [25]. Yüksek silindir basıncı ve sıcaklığına bağlı olarak meydana gelen yüksek miktarlardaki $\mathrm{NO}_{\mathrm{x}}$ emisyonları, yüksek kendi kendine tutuşma sicaklığı, yanma vuruntusu, geri tepme gibi olumsuz yanma olayları meydana gelebilmektedir $[25,27,28]$. Ayrıca, yeryüzünde hidrojenin doğal kaynağı bulunmadığından dolayı her zaman başka kaynaklardan üretilmeye ihtiyaç duyulmaktadır [21]. Yüksek kendiliğinden tutuşma sıcaklığından dolayı hidrojen gazının bir buji veya kızdırma bujisi olmadan doğrudan tek yakıt olarak IYM'de kullanımı uygun olmayıp, belirli oranlarda karışım oluşturularak çift yakıt modunda kullanılabilmektedir [34,36,37].

Sıkıştırma ile ateşlemeli motorda hidrojen gazı çift yakıt uygulaması işlemi genellikle; emme manifolduna sürekli enjeksiyon, emme manifolduna kontrollü enjeksiyon ve doğrudan yanma odasına kontrollü enjeksiyon olmak üzere üç farklı şekilde gerçekleştirilebilmektedir [21,34]. Emme manifolduna hidrojen gönderilmesi ve silindir içerisine alındıktan sonra pilot dizel yakıt tarafından tutuşmanın sağlanması, çift yakıtlı (hidrojen-dizel yakıtlı) dizel motorlarda en uygun yöntem olduğu ifade edilmektedir [38]. Emme manifolduna hidrojenin sürekli enjeksiyonu en basit yöntemdir. Ancak bu yöntemin uygulanmasında dikkat edilmesi gereken önemli bir konu ise hidrojenin alevlenmesi durumunda alevlerin hidrojen tüpüne ulaşmaması için bir alev tutucudan geçirilmesidir [21].

Sıkıştırma ile ateşlemeli motorlarda hidrojenin ikincil yakıt olarak kullanılması ile ilgili yapılan çalışmalar incelendiğinde; genel olarak hidrojendizel [32,39,40], hidrojen-biyodizel [41-43], hidrojen-metan gazı [38,44,45], hidrojen-biyogaz [45-47], hidrojen-doğal gaz [48-50] ve hidrojenLPG [51-53] gibi uygulamalara rastlamak mümkündür. Sıkıştırma ile ateşlemeli motorlarda hidrojen-dizel uygulamasının motor performansına ve emisyonlarına etkisi ile ilgili oldukça fazla çalışma yapılmış olup aşağıda özetlenmiştir.

Jhang ve arkadaşları [18] yapmış oldukları çalışmada, hacimsel olarak farklı oranlardaki dizelhidrojen karışımlarının $(\% 0, \% 0,6$ ve $\% 1,2)$ sıkıştırma ile ateşlemeli motorun performansına ve emisyonlarına etkisini incelemişlerdir. Deneyler sıkıştırma ile ateşlemeli motorun rölanti ve farklı motor yükü durumları için gerçekleştirilmiştir. Çalışmadan elde edilen sonuçlara göre; hidrojen miktarındaki artış ile özgül yakıt tüketimi (ÖYT) azalırken, termal verimliliği artmıştır. Hidrojen 
ilavesi, $\mathrm{CO}_{2}$ ve $\mathrm{CO}$ emisyonlarını azaltmıştır. Yüksek motor yükünde, düşük seviye hidrojen ilavesi $\mathrm{CO}$ ve $\mathrm{CO}_{2}$ emisyonlarını azaltırken, THC ve $\mathrm{NO}_{\mathrm{x}}$ emisyonlarını arttırmıştır.

Yilmaz ve Gümüs [54], emme havası hidrojenle zenginleştirilmiş dizel yakıt ile çalş̧an common rail enjeksiyon sistemine sahip dört silindirli, dört zamanlı 1.461-L bir dizel motorunun performans ve egzoz emisyonlarını incelemişlerdir. Hidrojen miktarı 20 l/d ve 40 l/d, motor yükü $50 \mathrm{Nm}, 75 \mathrm{Nm}$ ve $100 \mathrm{Nm}$ durumları için yapılan çalışmada, termal veriminde iyileşme olurken, ÖYT'de azalma elde edilmiştir. Hidrojen zenginleştirmesi ile $\mathrm{HC}, \mathrm{CO}_{2}$ emisyonlarını ve 1 sı salınım oranının düștüğü ve tüm test koşullar altında egzoz gazı sıcaklıklarının ve silindir basınçlarının arttığı görülmüştür. $\mathrm{NO}_{\mathrm{x}}$ emisyonları H20 durumunda azalırken, H40 durumunda arttı̆̆ tespit edilmiştir.

Sharma ve Dhar [32], hidrojen ve dizel yakıtı ile çalışan sabit hız dizel motorunda çift yakıt modlu yanma üzerine araştırma yapmışlardır. Hidrojen enerji payı (HES) $\% 5, \% 10$ ve $\% 20$ için farklı motor yüklerinde $(\% 25, \% 50$ ve $\% 75)$ motor performansını ve egzoz emisyonlarını incelemişlerdir. Test edilen aralık için hidrojen katkısının termal verimliliği ve ÖYT üzerinde hafif olumsuz etkisi gözlenmiştir. \%75 yükte $\mathrm{NO}_{\mathrm{x}}$ emisyonları \%20 HES ile \%9 artmıştır. Bu durum silindir içi sıcaklığının daha yüksek yüklerde hidrojen katkısı ile arttığını göstermektedir. Düşük ve orta yüklerde zararlı emisyonların azaltılmasında hidrojen katkısının yararlı olduğu görülmüştür.

Deb ve arkadaşları [28] tek silindirli, dört zamanlı ve hava soğutmalı bir motorda dizel ve hidrojen katkısının motor performansına ve emisyonlarına etkisini incelemişlerdir. Yapılan çalışmada hidrojen katkıs1, hidrojen gazının LPG-LNG enjektörü kullanarak emme manifolduna püskürtülmesi ile gerçekleștirilmiștir. Hidrojen miktarının artıșına bağlı olarak termal verimde iyileşme ve özgül enerji tüketiminde azalma gözlemlenmiştir. Özgül $\mathrm{CO}$, $\mathrm{CO}_{2}$ ve is emisyonları azalırken, $\mathrm{NO}_{x}$ emisyonlarında artış meydana gelmiştir. Silindirlere alınan hidrojen miktarının artması silindir içi basınçları ve $1 \mathrm{~s} 1$ çıkış oranlarını artırmıştır.
Sandalcı ve Karagöz [55] tarafindan yapılan deneysel çalışmada, tek silindirli, dört zamanlı ve su soğutmalı bir dizel motor, hidrojen-dizel ikili yakıt kullanılarak çalıştırılmış, motor performans ve emisyon değerleri incelenmiştir. Deneyler $1300 \mathrm{~d} / \mathrm{d}$ sabit motor hızında ve $5,1 \mathrm{~kW}$ sabit motor gücünde gerçekleştirilmiştir. Bu çalışmada, hidrojen gazı bir LPG-CNG enjektörü kullanılarak emme manifolduna gönderilmiş ve pilot dizel yakıtı ile dolgunun ateşlenmesi sağlanmıştır. HES'in \%16, $\% 36$ ve \%46 olarak belirlendiği çalışmada, hidrojen oranının artışı ile birlikte termal verim düşerken, ÖYT artış göstermiştir. Artan hidrojen oranı $\mathrm{CO}$, $\mathrm{CO}_{2}$ ve is emisyonlarında azalmaya, $\mathrm{HC}$ emisyonlarında ise artışa neden olmuştur. $\mathrm{NO}_{\mathrm{x}}$ emisyonları hidrojen miktarı \%16 durumunda değişmezken, hidrojen miktarındaki artış (\%36 ve \%46) ile $\mathrm{NO}_{\mathrm{x}}$ emisyonları da artı̧ göstermiştir.

Zhou ve arkadaşları [56] tarafindan doğal emişli bir dizel motorda HES'in $\% 10, \% 20, \% 30$ ve $\% 40$ olduğu deneyler gerçekleştirilmiş, motor performansı ve egzoz emisyonlarındaki değişim incelenmiştir. Motorun orta ve yüksek yüklerinde performansta iyileşmeler meydana gelmiştir. Yüksek yükte \%30'dan fazla hidrojen eklenmesi durumunda 1sı çıkış hızı artmış, tutuşma gecikmesi ve yanma süresi azalmıştır. $\mathrm{HC}$ emisyonları düşük ve orta yüklerde azalmıştır. $\mathrm{NO}_{\mathrm{x}}$ emisyonları düşük yüklerde azalırken yüksek yüklerde artmıştır.

Saravanan ve Nagarajan [36] yapmış oldukları çalışmada, hidrojen ile zenginleştirilmiş tek silindirli, dört zamanlı ve su soğutmalı bir dizel motorun performans ve emisyon karakteristiklerini incelemişlerdir. Dizel yakıtı kademeli olarak azaltılmış ve azalan yakıt yerine emme manifolduna hidrojen gazı gönderilerek motorun sabit bir devir $(1500 \mathrm{~d} / \mathrm{d})$ çalışması sağlanmıştır. Tam yükte $\mathrm{NO}_{\mathrm{x}}$ emisyonu dizel çalışmaya göre önemli oranda artarken, hem is hem de partikül madde miktarı yaklaşık \%50 oranında azalmıştır. Termal verimi $\% 30$ 'luk hidrojen zenginleşmesiyle \%22,78'den \%27,9'a çıkmıştır. En iyi sonuçlar \%30 hidrojen oranında elde edilmiştir.

Yapılan literatür incelemesinde, dizel yakıtına hidrojen katkısı yapılarak emisyonlara etkisinin incelendiği çalışmalarda genel olarak doğal emişli 
dizel motorların kullanıldığı görülmüştür. Turbo şarjlı motorlar yüksek oranda hava fazlalığı ile çalıştıklarından dolayı, çalışma sonucunda elde edilen sonuçlar da farklılık gösterebilmektedir. Dolayısıyla yapılan bu çalışmada; dört zamanlı, dört silindirli, su soğutmalı, turbo şarjlı ve Common-Rail yakıt püskürtme sistemine sahip modern bir motorda, emme havasına hidrojen ilavesinin dizel motorunun egzoz emisyonlarına etkisi deneysel olarak incelenmiştir.

\section{MATERYAL VE METOT}

Yapılan çalışmada, Common Rail yakıt sistemine sahip dört silindirli, dört zamanlı, su soğutmalı, turbo şarjlı ve $48 \mathrm{~kW}$ dizel motor kullanılmıştır. Deney motoru, maksimum gücü $150 \mathrm{~kW}$ ve maksimum devri $8000 \mathrm{~d} / \mathrm{d}$ olan su soğutmalı eddy current dinamometre kullanılarak yüklenmiştir.

Veri toplama işlemine geçilmeden önce deney motorunun soğutma suyu sicaklığ $80{ }^{\circ} \mathrm{C}$ 'ye kadar ulaşması beklenmiş, motor kararlı çalışır hale getirilmiştir.

Deneyler üç kez tekrarlanmış ve ortalamaları alınarak değerlendirilmiştir. Çalışma kapsamındaki bütün testler $1750 \mathrm{~d} / \mathrm{d}$ sabit devirde, $40 \mathrm{Nm}, 60 \mathrm{Nm}$ ve $80 \mathrm{Nm}$ motor yüklerinde gerçekleştirilmiştir.

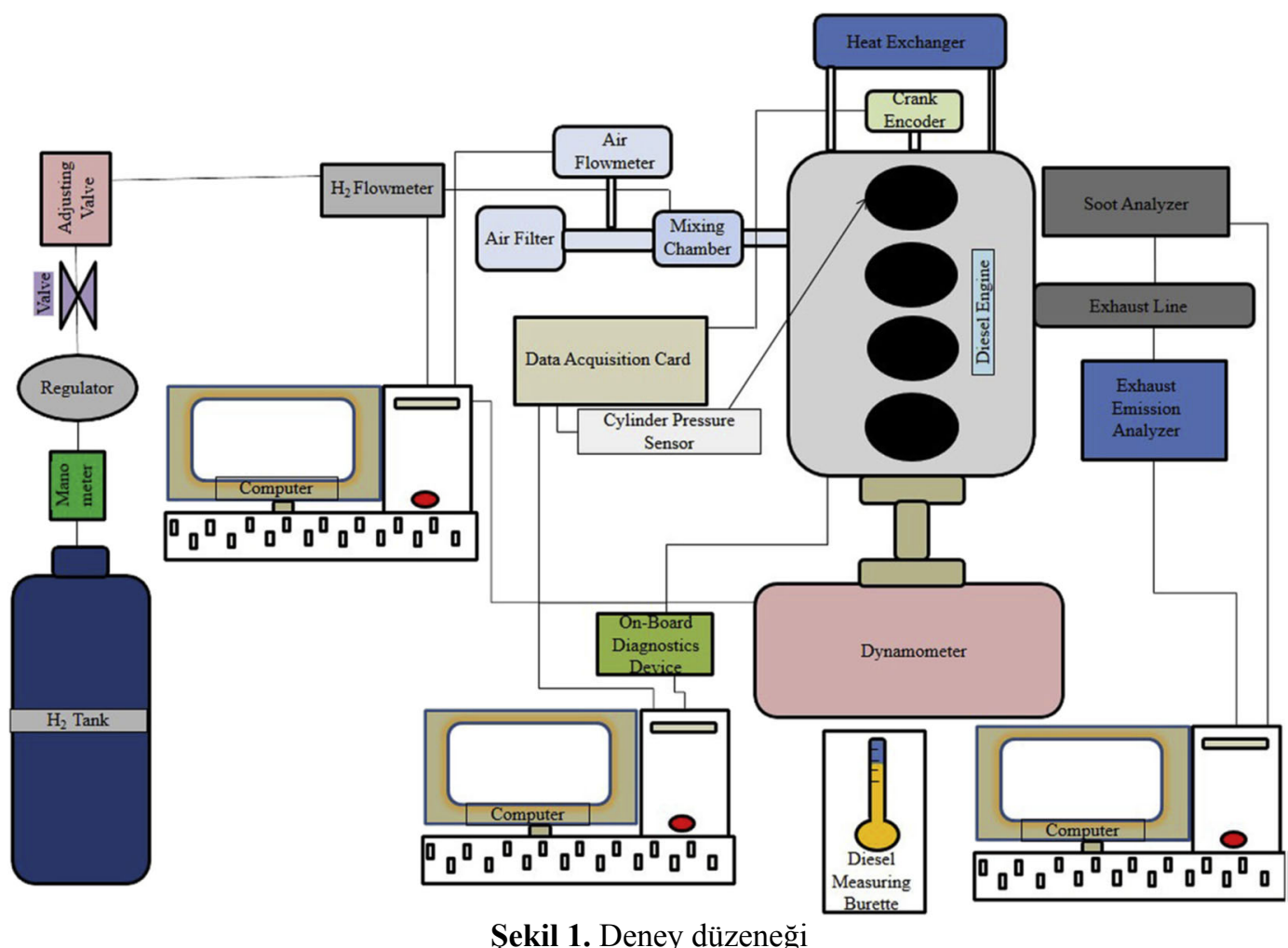

Emme manifoldu ve hava filtresi arasında basit bir karıştırma odası yerleştirilmiştir. Karıştırma odasına dakikada 10,20 ve 30 litre debide (1/d) hidrojen gazı gönderilerek hava ile karışması sağlanmış ve daha sonra silindir içerisine alınmıştır. Deney düzeneğinin şematik görünümü Şekil 1'de

verilmiştir. Çalışmada kullanılan deney düzeneği referans [57]'de ayrıntılı olarak sunulmuştur.

Deneysel çalışmada kullanılan dizel motorunun emme havası, motor yağı, yakıt, egzoz, soğutma suyu giriş ve çıkış sıcaklıkları $\mathrm{K}$ tipi sıcaklık 
sensörleri kullanılarak ölçülmüştür. Deney motoruna ait bazı özellikler Çizelge 2'de verilmiştir.

Çizelge 2. Deney motorunun özellikleri

\begin{tabular}{|l|l|}
\hline Tip & Sıralı, turbo şarjlı \\
\hline Silindir hacmi & $1461 \mathrm{~cm}^{3}$ \\
\hline Çap & $76 \mathrm{~mm}$ \\
\hline Strok & $80,5 \mathrm{~mm}$ \\
\hline Silindir sayısı & 4 \\
\hline Valf sayısı & 8 \\
\hline Sıkıştırma oranı & $18,25 / 1$ \\
\hline Maksimum güç $(4000 \mathrm{~d} / \mathrm{d})$ & $48 \mathrm{~kW}$ \\
\hline Maksimum tork $(1750 \mathrm{~d} / \mathrm{d})$ & $160 \mathrm{Nm}$ \\
\hline Püskürtme tipi & Common-Rail \\
\hline
\end{tabular}

Çizelge 3. Egzoz emisyon cihazının özellikleri

\begin{tabular}{|l|c|c|}
\hline & Ölçüm Aralı̆̆ & Hassasiyet \\
\hline Karbondioksit $\left(\mathrm{CO}_{2}\right)$ & $\% 0-18$ vol. & $\% 0,01$ vol. \\
\hline Hidrokarbon $(\mathrm{HC})$ & $0-9999 \mathrm{ppm}$ & $1 \mathrm{ppm}$ \\
\hline Oksijen $\left(\mathrm{O}_{2}\right)$ & $\% 0-22 \mathrm{vol}$. & $\% 0,01 \mathrm{vol}$. \\
\hline Azot oksit $\left(\mathrm{NO}_{\mathrm{x}}\right)$ & $0-5000 \mathrm{ppm}$ & $1 \mathrm{ppm}$ \\
\hline Hava fazlalık katsayısı $(\mathrm{HFK})$ & $0,5-1,8$ & 0,001 \\
\hline İs $(\mathrm{K})$ & $0-10 \mathrm{~m}^{-1}$ & $0,01 \mathrm{~m}^{-1}$ \\
\hline
\end{tabular}

\section{BULGULAR VE TARTIŞMA}

Yapılan çalışmada, dört silindirli, turbo şarjlı bir dizel motoruna hidrojen ilavesinin egzoz emisyonları $\left(\mathrm{HC}, \mathrm{CO}_{2}, \mathrm{NO}_{\mathrm{x}}, \mathrm{O}_{2}\right.$ ve is emisyonları) üzerine etkisi deneysel olarak incelenmiş ve aşağıda grafikler halinde sunularak yorumlanmıştır.

\subsection{Toplam Hidrokarbon Emisyonları}

Hidrokarbon emisyonları, temel olarak karbon ve hidrojen bileşiklerinden meydana gelen fosil kaynaklı yakıtların eksik yanması sonucu oluşmaktadır. Tamamlanmamış yanma ve düşük silindir içi sıcaklığı yanmamış hidrokarbonların başlıca sebeplerindendir [58]. Egzoz gazları içerisinde bulunan yanmamış hidrokarbonlar, genellikle toplam hidrokarbonlar (THC) olarak adlandırılmaktadırlar [59]. Hidrojen katkısının THC emisyonları üzerine etkisi Şekil 2'de gösterilmektedir. Şekil 2'den görüldüğü üzere, motor yükünün artışı ile THC emisyonlarında her bir yakıt için artmıştır.
Yüksek basınçlı bir hidrojen tüpünden elde edilen hidrojen gazının basıncını 1 bar değerine düşürmek için bir basınç regülatörü kullanılmıştır. Hidrojen boru hattı üzerine, herhangi bir geri tepme olasılığına karşı bir alev tutucu valf yerleştirilmiştir. Hidrojen gazının miktarını ayarlamak için \%1 1/d hassasiyetli dijital kütlesel akış ölçer kullanılmıştır.

Emisyon analizi, Bosch BEA 460 emisyon analizörü kullanılarak gerçekleştirilmiştir. Emisyon analizörü, egzoz gazı test modülü ve is emisyonu ölçüm modülü olmak üzere iki modüle sahiptir. Egzoz emisyon cihazının teknik özellikleri Çizelge 3'te görülmektedir.

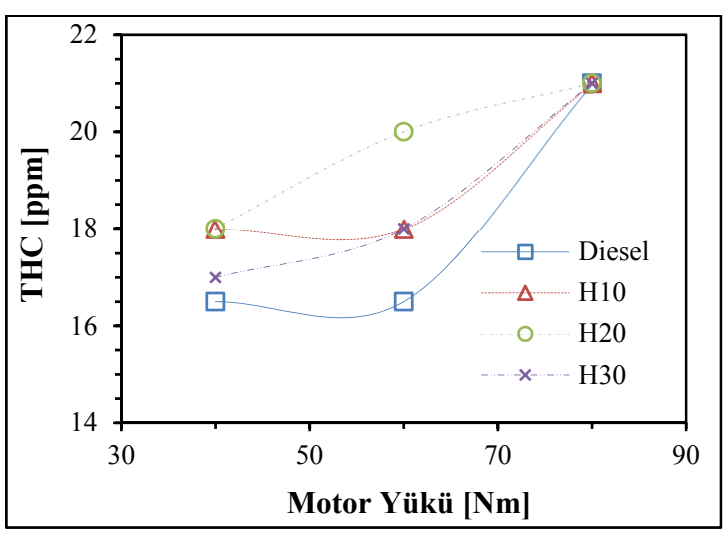

Şekil 2. Hidrojen katkısı ile toplam hidrokarbon emisyonlarının değişimi

Hidrojen katkısı ile birlikte THC emisyonlarında artış meydana gelmiş, dizel yakıtı ile karşılaştırıldığında en büyük artış $60 \mathrm{Nm}$ motor yükünde ve 20 1/d hidrojen katkısı ile \%21,2 olarak elde edilmiştir. Yüksek motor yükünde $(80 \mathrm{Nm})$ dizel yakıtı ve hidrojen katkısı ile elde edilen THC emisyon değerlerinin aynı seviyelerde olduğu görülmüştür. 
Hidrojen katkısının dizel motor performansı ve egzoz emisyonlarına etkisini araştıran Zhou ve arkadaşları [56] yapmış oldukları çalışmada, $\% 10-20$ oranlarında hidrojen katkısı ile THC emisyonlarında artış tespit etmişlerdir. Yüksek motor yüklerinde dizel yakıtının yanması için gerekli oksijen miktarının azalmasından dolayı hidrojen katkısı ile yüksek motor yüklerinde $\mathrm{HC}$ emisyonlarının arttığı ifade edilmektedir [23]. Yine Karagöz ve arkadaşları [60], hidrojenin emme manifolduna enjekte edilmesinin emme zamanında emme havası akışı için ek bir direnç oluşturduğu ve volümetrik verimde azalmaya neden olduğu belirtilmiştir. Giriş havasındaki azalmadan dolayı her bir motor yükü durumunda THC emisyonlarında artış meydana geldiği ifade edilmiştir. THC emisyonlarındaki artışın bir başka sebebi olarak da silindir içerisindeki yağlama yağının yanması gösterilmektedir [61]. Hidrojen katkısı ile THC emisyonlarında meydana gelen artış, literatürde tarafından yapılan çalışmalar $[18,23,55,56,60]$ ile benzerlik göstermektedir.

\subsection{Karbondioksit Emisyonları}

Fosil kaynaklı yakıt içerisindeki karbon ile oksijenin tam yanması sonucu bir tür sera gazı olan karbon dioksit $\left(\mathrm{CO}_{2}\right)$ emisyonu oluşmaktadır [23]. Şekil 3'te hidrojen katkısına bağlı olarak $\mathrm{CO}_{2}$ emisyonlarındaki değişim verilmiştir.

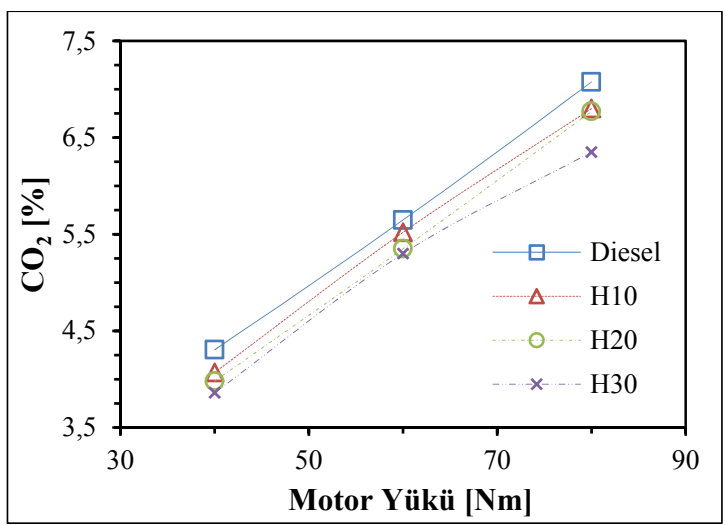

Şekil 3. Hidrojen katkısı ile karbondioksit emisyonlarının değişimi

Şekil 3 'ten görüldüğü üzere, her bir yakıt için artan motor yükü ile birlikte $\mathrm{CO}_{2}$ emisyonları da artmıştır. $\mathrm{CO}_{2}$ emisyonları stokiyometrik havayakıt karışımı durumunda yüksek değerine ulaşmaktadır. Motor yükündeki artış ile birlikte silindir içerisindeki karışım zenginleşerek stokiyometrik karışıma yaklaşmakta, dolayısıyla da $\mathrm{CO}_{2}$ emisyonlarında artış olmaktadır [62].

Hidrojenin katk1 maddesi olarak IYYM'lerde kullanılmasının yararlarından biri de $\mathrm{CO}_{2}$ emisyonlarında azalmaya neden olmasidır [30]. Dizel yakıtı ile karşılaştırıldığında, hidrojen oranının artışı ile birlikte her bir motor yükü için $\mathrm{CO}_{2}$ emisyonunda azalma meydana gelmiştir. $\mathrm{Bu}$ azalma $40 \mathrm{Nm}$ motor yükünde $10 \mathrm{l} / \mathrm{d}, 20 \mathrm{l} / \mathrm{d}$ ve 30 1/d hidrojen akış oranları için sırasıyla \%5,6, $\% 7,5$ ve $\% 10,3$ olarak ölçülmüştür. $60 \mathrm{Nm}$ motor yükü için sırasıyla $\% 2,2, \% 5,2$ ve $\% 6,1,80 \mathrm{Nm}$ motor yükünde ise sirasıly $\% 3,8, \%$ 4,3 ve $\% 10,2$ olarak ölçülmüştür. Dizel yakıtına göre karbondioksit emisyonundaki maksimum azalma $40 \mathrm{Nm}$ motor yükünde ve $30 \mathrm{l} / \mathrm{d}$ hidrojen akış oranında \%10,3 olarak elde edilmiştir. Hidrojen katkısı ile karbondioksit emisyonunda meydana gelen azalmanın sebebi olarak hidrojenin içerisinde karbon atomunun bulunmaması gösterilmektedir $[23,62]$. Daha önce literatürde yapılan çalışmalarda da $[23,54,62-65]$ benzer sonuçlar elde edilmiştir.

\subsection{NO Emisyonları}

Genel olarak \%90-95 NO, \%5-10 $\mathrm{NO}_{2}$ 'den ve düşük miktarda da $\mathrm{N}_{2} \mathrm{O}$ 'dan meydana gelen $\mathrm{NO}_{\mathrm{x}}$ emisyonlarının oluşumu [30,66], yanma sıcaklığ1, oksijen konsantrasyonu ve azotun yüksek sıcaklığa maruz kalma süresi olmak üzere üç temel etmene bağlıdır $\quad[30,33,67,68] . \quad 1800 \quad \mathrm{~K} \quad$ altındaki sıcaklıklarda $\mathrm{NO}_{\mathrm{x}}$ oluşum reaksiyon hızı oldukça düşüktür [30]. $\mathrm{NO}_{\mathrm{x}}$ emisyonu, atmosferi kirletmekte ve asit yağmuruna neden olmaktadır [23]. Hidrojen ilavesiyle farklı motor yükleri için $\mathrm{NO}_{\mathrm{x}}$ emisyonlarındaki değişim Şekil 4'te gösterilmiştir.

Şekil 4'ten görüldüğü üzere, her bir yakıt için artan motor yükü ile $\mathrm{NO}_{\mathrm{x}}$ emisyonları da artmıştır. Düşük motor yükünde $(40 \mathrm{Nm})$ dizel yakıtına hidrojen katkısı $\mathrm{NO}_{\mathrm{x}}$ emisyonlarında azalmaya neden olmuş, en fazla azalma hidrojen miktarının 30 l/d durumunda \%15,9 olarak elde edilmiştir. Artan 
motor yükü ile (40 Nm'den sonra) $\mathrm{NO}_{\mathrm{x}}$ emisyon değerinde dizel yakıtına göre hidrojen katkısı ile küçük oranlarda artış görülmüştür. Özellikle miktarının 20 1/d durumunda, artan motor yükü ile $\mathrm{NO}_{\mathrm{x}}$ emisyonu dizel yakıtına göre daha yüksek değerlere ulaşmıştır. Genel olarak emme havasına hidrojen ilavesinin $\mathrm{NO}_{\mathrm{x}}$ emisyonları üzerine olumlu etkisi olduğu görülmüştür.

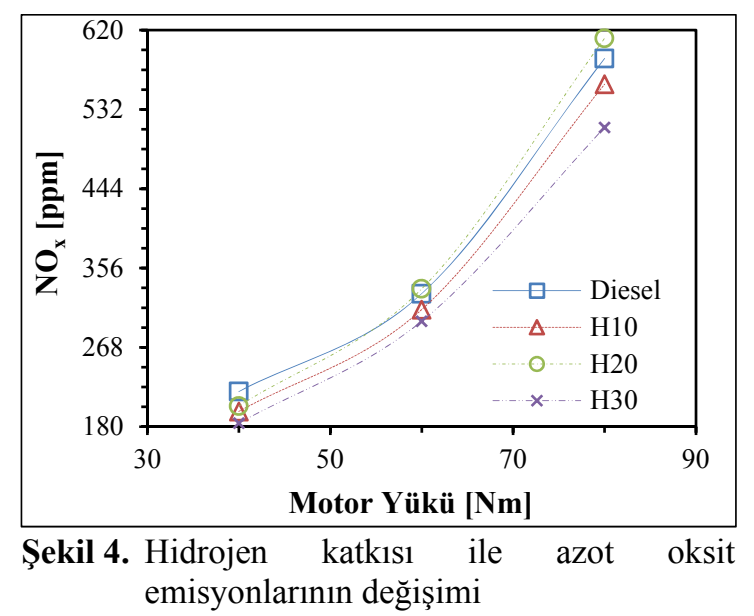

Literatürde hidrojen katkısı ile düşük yüklerde $\mathrm{NO}_{\mathrm{x}}$ emisyonları azalırken, orta ve yüksek yüklerde artış gösterdiği ifade edilmektedir [69]. Wu ve $\mathrm{Wu}$ [23] tarafindan yapılan çalışmada, \%60 motor yükünde ve $\% 20$ hidrojen katkı oranında saf dizel yakıtına göre $\mathrm{NO}_{\mathrm{x}}$ emisyonlarında artış olduğu rapor edilmiştir. Bu durumun sebebi olarak, artan motor yükü ile hidrojen enerjisinin payı aynı kalmakta, ancak daha fazla hidrojen kütlesi tüketilmekte ve hidrojenin silindir içi sıcaklığını arttırmak için yüksek bir 1sıl değere sahip olması gösterilmektedir. Sharma ve Dhar [32] tarafından yapılan çalışma sonucunda, yüksek motor yüklerinde hidrojen katkısının silindir içi sıcaklıklarını artmasından dolayı $\mathrm{NO}_{\mathrm{x}}$ emisyonlarında artışa neden olduğu ifade edilmektedir. Jhang ve arkadaşları [18] tarafından yapılan çalışmada, hidrojen ilavesinin, boşta çalışma ve düşük (\%25) motor yükleme koşullarında $\mathrm{NO}_{\mathrm{x}}$ emisyonlarını düşürürken, orta ve yüksek yükleme koşullarında $\mathrm{NO}_{\mathrm{x}}$ emisyonlarını artırdığı ifade edilmiştir. Yine Christodoulou ve Megaritis [70] tarafından yapılan çalışmada, düşük motor yüklerinde $\mathrm{NO}_{\mathrm{x}}$ emisyonlarında önemli bir değişim olmazken, yüksek motor yüklerinde hidrojen katkısı ile $\mathrm{NO}_{\mathrm{x}}$ emisyonlarının arttığı belirlenmiştir. Dolayısıyla elde edilen sonuçların daha önceki literatür çalışmalarıyla uyum içerisinde olduğu görülmüştür.

\section{4. $\mathrm{O}_{2}$ Emisyonları}

IYYM'lerde yanmanın oluşabilmesi için en önemli parametrelerden bir tanesi de ortamdaki $\mathrm{O}_{2}$ miktarıdır [71,72]. Hava-yakıt oranını önemli derecede etkileyen oksijen miktarındaki artış, yanma işlemini iyileştirmekte ve dolaysıyla da motor performansının artmasına neden olmaktadır [72]. Hidrojen katkısının motor yüküne bağlı olarak $\mathrm{O}_{2}$ emisyonlarına etkisi Şekil 5 'te verilmiştir.

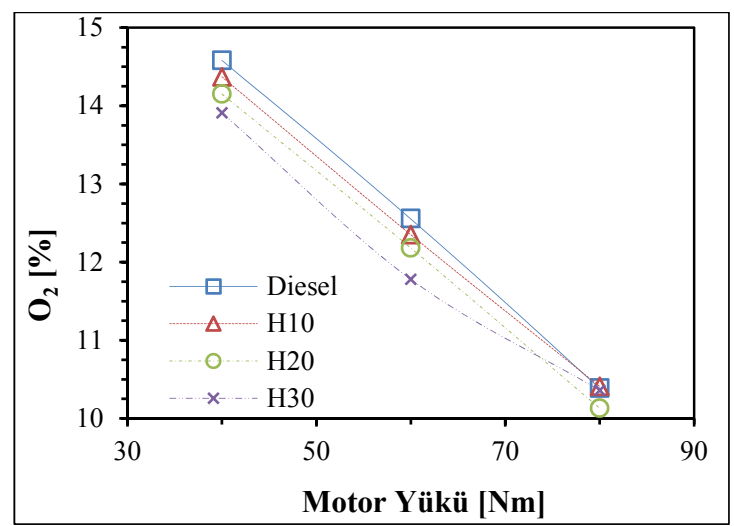

Şekil 5. Hidrojen katkısı ile $\mathrm{O}_{2}$ emisyonlarının değişimi

Şekil 5'ten görüldüğü üzere, dizel yakıtı ve hidrojen katkısı durumunda elde edilen $\mathrm{O}_{2}$ emisyonları benzer eğilim göstermişlerdir. Genel olarak artan motor yükü ile birlikte her bir yakıt için $\mathrm{O}_{2}$ emisyonu azalmıştır. Artan motor yükü ile birlikte silindire gönderilen yakıt miktarı da arttığından dolayı karışımın zenginleşmekte, hava/yakıt oranının azalmakta ve dolayısıyla da tüm $\mathrm{O}_{2}$ 'nin yanma işleminde kullanılması sonucu egzoz emisyonunda görülen $\mathrm{O}_{2}$ miktarının azalmasına neden olmaktadır [62].

Dizel yakıtına göre, hidrojen katkısı ile $\mathrm{O}_{2}$ emisyonlarında azalma meydana gelmiştir. Her bir motor yükü için dizel yakıtına göre hidrojen katkısı ile $\mathrm{O}_{2}$ emisyonundaki azalma; $40 \mathrm{Nm}$ motor yükünde 10 1/d, 20 l/d ve 30 l/d hidrojen akış 
oranları için sırasıyla \%1,4, \%2,9 ve $\% 4,6$ olarak ölçülmüştür. $60 \mathrm{Nm}$ motor yükünde $\% 1,6, \% 2,9$ ve $\% 6,1,80 \mathrm{Nm}$ motor yükünde ise $\% 0,2, \% 2,4$ ve $\% 0,2$ olarak ölçülmüştür. Dizel yakıtına göre $\mathrm{O}_{2}$ emisyonundaki maksimum azalma, $60 \mathrm{Nm}$ motor yükünde ve hidrojen akış oranı $30 \mathrm{l} / \mathrm{d}$ ile $\% 6,1$ olarak elde edilmiştir. Hidrojen katkısının $\mathrm{O}_{2}$ emisyonu üzerine etkisinin oldukça düşük olduğu görülmüştür. Literatür tarafindan da [62,72] benzer sonuçların elde edildiği görülmüştür.

\section{5. İs Emisyonları}

IYYM'nin emisyon davranışını belirlemek için önemli bir parametre olan is emisyonu [73]; yüksek basınç, yüksek sıcaklık ve oksijenin eksik olduğu yanma koşullarından meydana gelmektedir [23]. Yanma ișleminde karbona göre daha aktif olan hidrojen, karbondan önce ortamdaki oksijen ile reaksiyona girmekte ve dolayısıyla oksijen ve yeterli süre bulunmayan karbon [74] egzoz gazı içerisinde is emisyonu olarak görülmektedir. İs emisyonu, yanma sırasında oksijen eksikliğinden meydana gelen, azalan hava/yakıt oranı ile artış gösteren bir emisyondur [7,58]. Genellikle dizel motorlarında görülen is emisyonu [74], yakıtın eksik yanması sonucunda oluşmaktadır [73].

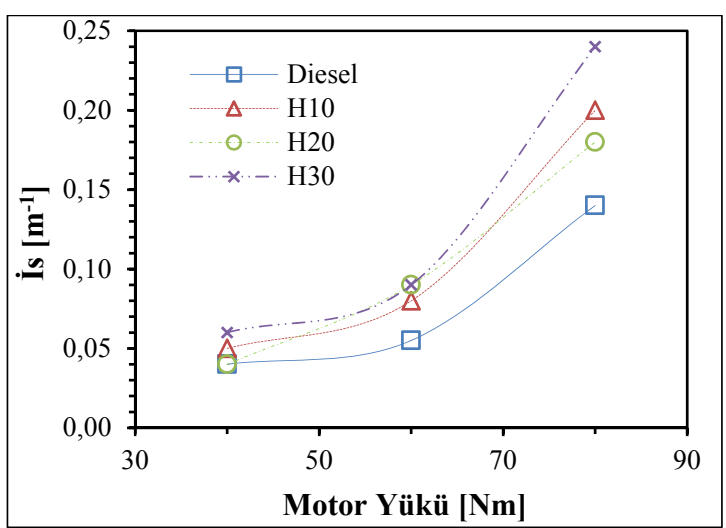

Şekil 6. Hidrojen katkısı ile is emisyonlarının değişimi

Şekil 6'da is emisyonunun hidrojen katkı oranı ile motor yüküne bağlı olarak değişimi verilmiştir. Şekilden görüldügüu üzere, artan motor yükü ile is emisyonları her bir test yakıtı için artmıştır. Dizel yakıtı ile karşılaştırıldığında, hidrojen katkısı ile birlikte her bir motor yükü için is emisyonlarının arttığı görülmüştür. Literatürde, artan motor yükü ile birlikte silindirlere alınan dizel yakıtının miktarının arttığ 1 ve bu durumun is emisyonlarını artırdığ 1 ifade edilmektedir [46,61,73-75].

Benzer şekilde, Zhou ve arkadaşları [76], hidrojen ilavesinin dizel yakıtının oksidasyonu üzerine etkisinin motorun yüküne bağlı olduğunu ifade etmiştir. Yüksek motor yüklerinde hidrojen katkısından dolayı yanma odasında oksijen miktarının azalması, is parçacıklarının oksidasyonunun olumsuz yönde etkileyerek is emisyonlarının artışına neden olduğunu belirtmişlerdir. Pundir ve Kumar [77] tarafından yapılan çalışmada, \%90 motor yükünde artan hidrojen oranı ile is emisyonunun da arttığı, \%100 motor yükünde hidrojen oranının artışı ile (\%20'ye kadar) is emisyonunun azalırken, artan hidrojen oranı ile ani bir artışın olduğu görülmüştür.

\section{SONUÇLAR}

Yapılan çalışmada dört zamanlı, dört silindirli, su soğutmalı, turbo şarjlı ve Common-Rail yakıt püskürtme sistemine sahip dizel motorunun emme havasına hidrojen ilavesinin egzoz emisyonları üzerine etkisi deneysel olarak incelenmiştir. Elde edilen sonuçlar, saf dizel yakıtı kullanımı durumunda elde edilen sonuçlar ile karşılaştırılmıştır. Çalışmada elde edilen sonuçlar aşağıda listelenmiştir;

- Hidrojen katkısı genel olarak THC emisyonlarında artışa neden olmuş, dizel yakıtına göre hidrojen katkısı ile meydana gelen en büyük artış $60 \mathrm{Nm}$ motor yükünde ve \%20 hidrojen katkısı ile \%21,2 olarak elde edilmiştir.

- $\mathrm{CO}_{2}$ emisyonlarında, deneysel çalışmanın gerçekleştirildiği tüm şartlarda dizel yakıtına göre azalma meydana gelmiştir. $\mathrm{CO}_{2}$ emisyonlarındaki maksimum azalma, $40 \mathrm{Nm}$ motor yükünde ve 30 l/d hidrojen akış oranında \%10,3 olarak ölçülmüştür.

- Düşük motor yükünde (40 Nm) emme havasına hidrojen katkısı ile $\mathrm{NO}_{\mathrm{x}}$ emisyonlarında azalma görülmüş, en fazla azalma hidrojen akış oranı 30 1/d durumunda \%15,9 olarak elde edilmiştir. 
Özellikle 20 l/d hidrojen akış oranında, artan motor yükü ile (40 Nm'den sonra) birlikte $\mathrm{NO}_{\mathrm{x}}$ emisyonlarında dizel yakıtına göre küçük oranlarda artış meydana gelmiş, en yüksek artış $80 \mathrm{Nm}$ motor yükünde, $20 \mathrm{l} / \mathrm{d}$ hidrojen akış oranı ile \%3,8 olarak ölçülmüştür.

- Her bir motor yükü için hidrojen katkısı ile $\mathrm{O}_{2}$ emisyonlarında azalma meydana gelmiştir. Dizel yakıtına göre $\mathrm{O}_{2}$ emisyonundaki maksimum azalma $60 \mathrm{Nm}$ motor yükünde ve 30 l/d hidrojen akış oranı ile $\% 6,1$ olarak elde edilmiştir. Hidrojen katkısının $\mathrm{O}_{2}$ emisyonu üzerine etkisinin oldukça düşük olduğu görülmüştür.

- Dizel yakıt ile çalışmayla kıyaslandığında, hidrojen katkısı ile is emisyonlarında artış meydana gelmiştir. Hidrojen katkı oranı ve motor yükündeki artış genel olarak is emisyonu da artırmıştır.

Çalışmadan elde edilen sonuçlara göre, hidrojen gazının turbo şarjlı bir dizel motorda kullanımını ile egzoz emisyonlarında iyileşmelerin sağlanabileceğini görülmüştür. Hidrojen katkısının fosil kaynaklı dizel yakıtının yanması sonucu oluşan $\mathrm{CO}_{2}, \mathrm{O}_{2}$ ve $\mathrm{NO}_{\mathrm{x}}$ emisyonlarının azaltılmasında yakıt katkısı olarak kullanılabileceği ifade edilebilir.

\section{TEŞEKKÜR}

Yazarlar, bu çalışmayı FEN-E-140312-0046 numaralı proje ile destekleyen Marmara Üniversitesi Bilimsel Araştırma Projeleri Komisyonu'na teşekkür eder.

\section{KAYNAKLAR}

1. Fayyazbakhsh, A., Pirouzfar, V., 2017. Comprehensive Overview on Diesel Additives to Reduce Emissions, Enhance Fuel Properties and Improve Engine Performance, Renewable and Sustainable Energy Reviews, 74, 891-901.

2. Pullagura, G., Kumar, K.R., Verma, P.C., Jaiswal, A., Prakash, R., Murugan, S., 2012. Experimental Investigation of Hydrogen Enrichment on Performance and Emission Behaviour of Compression Ignition Engine,
International Journal of Engineering Science and Technology (IJEST), 4(03), 1223-1232.

3. Firat, M., Okcu, M., Varol, Y., 2017. Investigation of Hydrogen Enrichment on Combustion Characteristics, Performance and Emissions of Diesel Engines, Science and Eng. J of Firat Univ. 29(1),101-107.

4. Yu, X., Du, Y., Sun, P., Liu, L., Wu, H., Zuo, X., 2017. Effects of Hydrogen Direct Injection Strategy on Characteristics of Lean-burn Hydrogen-gasoline Engines, Fuel, 208, 602-611.

5. Arunkumar, M., Kannan, M., Murali, G., 2019. Experimental Studies on Engine Performance and Emission Characteristics Using Castor Biodiesel as Fuel in CI Engine, Renewable Energy, 131, 737-744.

6. Dharmaraja, J., Nguyen, D.D., Shobana, S., Saratale, G.D., Arvindnarayan, S., Atabani, A.E., Chang, S.W., Kumar, G., 2019. Engine Performance, Emission and Bio Characteristics of Rice Bran Oil Derived Biodiesel Blends, Fuel, 239, 153-161.

7. Emiroğlu, A.O., Şen, M., 2018. Combustion, Performance and Emission Characteristics of Various Alcohol Blends in a Single Cylinder Diesel Engine, Fuel, 212, 34-40.

8. Li, G., Lee, T.H., Liu, Z., Lee, C.F., Zhang, C., 2019. Effects of Injection Strategies on Combustion and Emission Characteristics of a Common-rail Diesel Engine Fueled with Isopropanol-butanol-ethanol and Diesel Blends, Renewable Energy, 130, 677-686.

9. Shim, E., Park, H., Bae, C., 2018. Intake Air Strategy for Low $\mathrm{HC}$ and $\mathrm{CO}$ Emissions in Dual-fuel (CNG-diesel) Premixed Charge Compression Ignition Engine, Applied Energy, 225, 1068-1077.

10. Yontar, A.A., Doğu, Y., 2018. Investigation of the Effects of Gasoline and CNG Fuels on a Dual Sequential Ignition Engine at Low and High Load Conditions, Fuel, 232, 114-123.

11. Long, Y., Li, G., Zhang, Z., Liang, J., Mao, L., Li, Y., 2018. Effects of Reformed Exhaust Gas Recirculation on the HC and CO Emissions of a Spark-ignition Engine Fueled with LNG, International Journal of Hydrogen Energy, 43(45), 21070-21078. 
12. Vinoth, T., Vasanthakumar, P., Krishnaraj, J., ArunSankar, S.K., Hariharan, J., Palanisamy, M., 2017. Experimental Investigation on LPG + Diesel Fuelled Engine with DEE Ignition Improver, Materials Today: Proceedings, 4(8), 9126-9132.

13. Musthafa, M.M., 2019. A Comparative Study on Coated and Uncoated Diesel Engine Performance and Emissions Running on Dual Fuel (LPG-biodiesel) with and Without Additive, Industrial Crops \& Products, 128, 194-198.

14. Kim, J., Chun, K.M., Song, S., Baek, H.K., Lee, S.W., 2018. Hydrogen Effects on the Combustion Stability, Performance and Emissions of a Turbo Gasoline Direct Injection Engine in Various Air/fuel Ratios, Applied Energy, 228, 1353-1361.

15. Tsujimura, T., Suzuki, Y., 2019. Development of a Large-sized Direct Injection Hydrogen Engine for a Stationary Power Generator, International Journal of Hydrogen Energy, 44(22), 11355-11369. https://doi.org/10.1016/j.ijhydene.2018.09.178

16. Serin, H., Yıldızhan, Ş., 2018. Hydrogen Addition to Tea Seed Oil Biodiesel: Performance and Emission Characteristics, International Journal of Hydrogen Energy, 43(38), 18020-18027.

17. Yilmaz, İ., Taştan, M., 2018. Investigation of Hydrogen Addition to Methanol-gasoline Blends in an SI Engine, International Journal of Hydrogen Energy, 43(44), 20252-20261.

18. Jhang, S.R., Chen, K.S., Lin, S.L., Lin, Y.C., Cheng, W.L., 2016. Reducing Pollutant Emissions from a Heavy-duty Diesel Engine by Using Hydrogen Additions, Fuel, 172, 89-95.

19. Ji, C., Cong, X., Wang, S., Shi, L., Su, T., Wang, D., 2018. Performance of a Hydrogen-blended Gasoline Direct Injection Engine Under Various Second Gasoline Direct Injection Timings, Energy Conversion and Management, 171, 1704-1711.

20. Akar, M.A., Kekilli, E., Bas, O., Yildizhan, S., Serin, H., Ozcanli, M., 2018. Hydrogen Enriched Waste Oil Biodiesel Usage in Compression Ignition Engine, International Journal of Hydrogen Energy, 43(38), 18046-18052.
21. Rocha, H.M.Z., Pereira, R.S., Nogueira, M.F.M., Belchior, C.R.P., Tostes, M.E.L., 2017. Experimental Investigation of Hydrogen Addition in the Intake Air of Compressed Ignition Engines Running on Biodiesel Blend, International Journal of Hydrogen Energy, 42(7), 4530-4539

22. Elsemary, I.M.M., Attia, A.A.A., Elnagar, K.H., Elaraqy, A.A.M., 2016. Experimental Investigation on Performance of Single Cylinder Spark İgnition Engine Fueled with Hydrogen-gasoline Mixture, Applied Thermal Engineering, 106, 850-854.

23. Wu, H.W., Wu, Z.Y., 2012. Investigation on Combustion Characteristics and Emissions of Diesel/hydrogen Mixtures by Using EnergyShare Method in a Diesel Engine, Applied Thermal Engineering, 42, 154-162.

24. Du, Y., Yu, X., Liu, L., Li, R., Zuo, X., Sun, Y., 2017. Effect of Addition of Hydrogen and Exhaust Gas Recirculation on Characteristics of Hydrogen Gasoline Engine, International Journal of Hydrogen Energy, 42(12), 8288-8298.

25. Navale, S.J., Kulkarni, R.R., Thipse, S.S., 2017. An Experimental Study on Performance, Emission and Combustion Parameters of Hydrogen Fueled Spark Ignition Engine with the Timed Manifold Injection System, International Journal of Hydrogen Energy, 42(12), 8299-8309.

26. Uludamar, E., Tosun, E., Tuccar, G., Yıldızhan, Ş., Çalık, A., Yıldırım, S., Serin, H., Özcanlı, M., 2017. Evaluation of Vibration Characteristics of a Hydroxyl (HHO) Gas Generator Installed Diesel Engine Fuelled with Different Diesel-biodiesel Blends, International Journal of Hydrogen Energy, 42(36), 23352-23360.

27. Krishnanunni, J., Bhatia, D., Das, L.M., 2017. Experimental and Modelling Investigations on the Performance and Emission Characteristics of a Single Cylinder Hydrogen Engine, International Journal of Hydrogen Energy, 42(49), 29574-29584.

28. Deb, M., Sastry, G.R.K., Bose, P.K., Banerjee, R., 2015. An Experimental Study on Combustion, Performance and Emission Analysis of a Single Cylinder, 4-stroke DI- 
Diesel Engine Using Hydrogen in Dual Fuel Mode of Operation, International Journal of Hydrogen Energy, 40(27), 8586-8598.

29. Koten, H., 2018. Hydrogen Effects on the Diesel Engine Performance and Emissions, International Journal of Hydrogen Energy, 43(22), 10511-10519.

30. Hosseini, S.M., Ahmadi, R., 2017. Performance and Emissions Characteristics in the Combustion of Co-fuel Diesel-hydrogen in a Heavy Duty Engine, Applied Energy, 205, 911-925.

31. Yan, F., Xu, L., Wang, Y., 2018. Application of Hydrogen Enriched Natural Gas in Spark Ignition IC Engines: from Fundamental Fuel Properties to Engine Performances and Emissions, Renewable and Sustainable Energy Reviews, 82(1), 1457-1488.

32. Sharma, P., Dhar, A., 2018. Effect of Hydrogen Supplementation on Engine Performance and Emissions, International Journal of Hydrogen Energy, 43(15), 7570-7580.

33. Yılmaz, İ.T., Gümüş, M., 2015. Çift Yakıtlı (hidrojen-dizel) Bir Motorda Yanma Karakteristiklerinin ve Egzoz Emisyonlarının İncelenmesi, 8. Transist Uluslararası Ulaşım Teknolojileri Sempozyumu ve Fuarı, 17-19 Aralık, İstanbul, Türkiye, 538-547.

34. Yilmaz, I.T., Demir, A., Gumus, M., 2017. Effects of Hydrogen Enrichment on Combustion Characteristics of a CI Engine, International Journal of Hydrogen Energy, 42(15), 10536-10546.

35. Pan, H., Pournazeri, S., Princevac, M., Miller, J.W., Mahalingam, S., Khan, M.Y., Jayaram, V., Welch, W.A., 2014. Effect of Hydrogen Addition on Criteria and Greenhouse Gas Emissions for a Marine Diesel Engine, International Journal of Hydrogen Energy, 39(21), 11336-11345.

36. Saravanan, N., Nagarajan, G., 2008. An Experimental Investigation of Hydrogenenriched Air Induction in a Diesel Engine System, International Journal of Hydrogen Energy, 33(6), 1769-1775.

37. Dimitriou, P., Kumar, M., Tsujimura, T., Suzuki, Y., 2018. Combustion and Emission Characteristics of a Hydrogen-diesel Dual-fuel
Engine, International Journal of Hydrogen Energy, 43(29), 13605-13617.

38. Karagöz, Y., Güler, İ., Sandalcı, T., Yüksel, L., Dalkılıç, A.s., Wongwises, S., 2016. Effects of Hydrogen and Methane Addition on Combustion Characteristics, Emissions, and Performance of a CI Engine, International Journal of Hydrogen Energy, 41(2), 1313-1325.

39. Ghazal, O.H., 2013. Performance and Combustion Characteristic of CI Engine Fueled with Hydrogen Enriched Diesel, International Journal of Hydrogen Energy, 38(35), 15469-15476.

40. Karagöz, Y., Güler, İ., Sandalcı, T., Yüksek, L., 2016. Effect of Hydrogen Enrichment on Combustion Characteristics, Emissions and Performance of a Diesel Engine, International Journal of Hydrogen Energy, 41(1), 656-665.

41. Aldhaidhawi, M., Chiriac, R., Badescu, V., Descombes, G., Podevin, P., 2017. Investigation on the Mixture Formation, Combustion Characteristics and Performance of a Diesel Engine Fueled with Diesel, Biodiesel B20 and Hydrogen Addition, International Journal of Hydrogen Energy, 42(26), 16793-16807.

42. Graham, S., 2017. The Viability of Biodiesel and Hydrogen as Complementary Fuel Vectors in a Hybrid Platform, International Journal of Hydrogen Energy, 42(30), 19331-19336.

43. Uludamar, E., 2018. Effect of Hydroxy and Hydrogen Gas Addition on Diesel Engine Fuelled with Microalgae Biodiesel, International Journal of Hydrogen Energy, 43(38), 18028-18036.

44. Mansor, M.R.A., Abbood, M.M., Mohamad, T.I., 2017. The Influence of Varying Hydrogenmethane-diesel Mixture Ratio on the Combustion Characteristics and Emissions of a Direct Injection Diesel, Engine, Fuel, 190, 281-291.

45. Talibi, M., Balachandran, R., Ladommatos, N., 2017. Influence of Combusting Methanehydrogen Mixtures on Compression-ignition Engine Exhaust Emissions and in-cylinder Gas Composition, International Journal of Hydrogen Energy, 42(4), 2381-2396.

46. Barik, D., Murugan, S., 2016. Experimental Investigation on the Behavior of a DI Diesel Engine Fueled with Raw Biogasediesel Dual 
Fuel at Different Injection Timing, Journal of the Energy Institute, 89, 373-388.

47. Verma, S., Das, L.M., Kaushik, S.C., Tyagi, S.K., 2018. An Experimental Investigation of Exergetic Performance and Emission Characteristics of Hydrogen Supplemented Biogas-diesel Dual Fuel Engine, International Journal of Hydrogen Energy, 43(4), 2452-2468.

48. Kakoee, A., Bakhshan, Y., Aval, S.M., Gharehghani, A., 2018. An Improvement of a Lean Burning Condition of Natural Gas/diesel RCCI Engine with a Pre-chamber by Using Hydrogen, Energy Conversion and Management 166, 489-499.

49. Singh, A.P., Pal, A., Agarwal, A.K., 2016. Comparative Particulate Characteristics of Hydrogen, CNG, HCNG, Gasoline and Diesel Fueled Engines, Fuel, 185, 491-499.

50. Baratta, M., Ambrosio, S., Iemmolo, D., Misul, D., 2017. Method for the Recognition of the Fuel Composition in $\mathrm{CNG}$ Engines Fed with Natural Gas/biofuel/hydrogen Blends, Journal of Natural Gas Science and Engineering, 40, 312-326.

51. Jemni, M.A., Kassem, S.H., Driss, Z., Abid, M.S., 2018. Effects of Hydrogen Enrichment and Injection Location on In-cylinder Flow Characteristics, Performance and Emissions of Gaseous LPG Engine, Energy, 150, 92-108.

52. Lata, D.B., Misra, A., Medhekar, S., 2012. Effect of Hydrogen and LPG Addition on the Efficiency and Emissions of a Dual Fuel Diesel Engine, International Journal of Hydrogen Energy, 37(7), 6084-6096

53. Lata, D.B., Misra, A., Medhekar, S., 2011. Investigations on the Combustion Parameters of a Dual Fuel Diesel Engine with Hydrogen and LPG as Secondary Fuels, International Journal of Hydrogen Energy, 36(21), 13808-13819.

54. Yilmaz, I.T., Gumus, M., 2018, Effects of Hydrogen Addition to the Intake Air on Performance and Emissions of Common Rail Diesel Engine, Energy, 142, 1104-1113.

55. Sandalcı, T., Karagöz, Y., 2014, Experimental Investigation of the Combustion Characteristics, Emissions and Performance of Hydrogen Port Fuel Injection in a Diesel Engine, International Journal of Hydrogen Energy, 39(32), 18480-18489.
56. Zhou, J.H., Cheung, C.S., Leung, C.W., 2014. Combustion, Performance, Regulated and Unregulated Emissions of a Diesel Engine with Hydrogen Addition, Applied Energy, 126, 1-12.

57. Yılmaz, İ.T., 2015. Düşük Isı Kayıplı Bir Dizel Motorda Çift Yakıt (biyogaz-dizel) Kullanımının Performans ve Emisyonlara Etkisi, Fen Bilimleri Enstitüsü, Doktora Tezi, 161 , İstanbul.

58. Asokan, M.A., Prabu, S.S., Kamesh, S., Khan, W., 2018. Performance, Combustion and Emission Characteristics of Diesel Engine Fuelled with Papaya and Watermelon Seed Oil Bio-diesel/Diesel blends, Energy, 145, 238-245.

59. Heywood, J.B.. 1988. Internal Combustion Engine Fundamentals. New York, NY, USA: McGraw Hill, Inc; 596-597.

60. Karagöz, Y., Sandalcı, T., Yüksek, R., Dalkılıç, A.S., 2015. Engine Performance and Emission Effects of Diesel Burns Enriched by Hydrogen on Different Engine Loads, International Journal of Hydrogen Energy, 40(20), 6702-6713.

61. Saravanan, N., Nagarajan, G., Narayanasamy, S., 2008. An Experimental Investigation on DI Diesel Engine with Hydrogen Fuel, Renewable Energy, 33, 415-421.

62. Morais, A.M., Justino, M.A.M., Valente, O.S., Hanriot, S.M., Sodre, J.R., 2013. Hydrogen Impacts on Performance and $\mathrm{CO}_{2}$ Emissions from a Diesel Power Generator, International Journal of Hydrogen Energy, 38(16), 6857-6864.

63. Liew, C., Li, H., Liu, S., Besch, M.C., Ralston, B., Clark, N., Huang, Y., 2012. Exhaust Emissions of a H2 Enriched Heavy-duty Diesel Engine Equipped with Cooled EGR and Variable Geometry Turbocharger, Fuel, 91, 155-163.

64. Miyamoto, T., Hasegawa, H., Mikami, M., Kojima, N., Kabashima, H., Urata, Y., 2011. Effect of Hydrogen Addition to Intake Gas on Combustion and Exhaust Emission Characteristics of a Diesel Engine, International Journal of Hydrogen Energy, 36(20), 13138-13149.

65. Tsujimura, T., Suzuki, Y., 2017. The Utilization of Hydrogen in Hydrogen/diesel Dual Fuel 
Engine, International Journal of Hydrogen Energy, 42(19), 14019-14029.

66. Alrazen, H.A., Talib, A.R.A., Adnan, R., Ahmad, K.A., 2016. A Review of the Effect of Hydrogen Addition on the Performance and Emissions of the Compression-ignition Engine, Renewable and Sustainable Energy Reviews, 54, 785-796.

67. Barrios, C.C., Saez, A.D., Hormigo, D., 2017. Influence of Hydrogen Addition on Combustion Characteristics and Particle Number and Size Distribution Emissions of a TDI Diesel Engine, Fuel, 199, 162-168.

68. Kacem, S.H., Jemni, M.A., Driss, Z., Abid, M.S., 2016. The Effect of H2 Enrichment on Incylinder Flow Behavior, Engine Performances and Exhaust Emissions: Case of LPG-hydrogen Engine, Applied Energy, 179, 961-971.

69. Chintala, V., Subramanian, K.A., 2017. A Comprehensive Review on Utilization of Hydrogen in a Compression Ignition Engine Under Dual Fuel Mode, Renewable and Sustainable Energy Reviews, 70, 472-491.

70. Christodoulou, F., Megaritis, A., 2013. Experimental Investigation of the Effects of Separate Hydrogen and Nitrogen Addition on the Emissions and Combustion of a Diesel Engine, International Journal of Hydrogen Energy, 38, 10126-10140.

71. Yesilyurt, M.K., Eryilmaz, T., Arslan, M., 2018. A Comparative Analysis of the Engine Performance, Exhaust Emissions and Combustion Behaviors of a Compression Ignition Engine Fuelled with Biodiesel/diesel/1butanol (C4 alcohol) and Biodiesel/diesel/npentanol (C5 alcohol) Fuel Blends, Energy, 165, 1332-1351.

72. Köse, H., 2012. Hidrojenin Çift Yakıt Modunda İlavesinin Motor Performans ve Emisyon Üzerine Etkisinin Deneysel Araştırılması, Selçuk Üniversitesi, Makine Eğitimi Anabilim Dalını, Yüksek Lisans Tezi, 90, Konya.

73. Kumar, S.S., Purushothaman, K., Rajan, K., 2017. Performance Analysis of a Biodiesel Fuelled Diesel Engine with the Effect of Alumina Coated Piston, Thermal Science, 21(1B), 489-498.

74. Yılmaz, İT., Gümüş, M., 2017. A Research on Biogas-diesel Dual Fuel Diesel Engine, Journal of the Faculty of Engineering and Architecture of Gazi University, 32(3), 919-927.

75. Mahla, S.K., Dhir, A., Gill, K.J.S., Cho, H.M., Lim, H.C., 2018. Influence of EGR on the Simultaneous Reduction of NOx-smoke Emissions Trade-off Under CNG-biodiesel Dual Fuel Engine, Energy, 152, 303-312.

76. Zhou, J.H., Cheung, C.S., Zhao, W.Z., Ning, Z., Leung, C.W., 2015, Impact of Intake Hydrogen Enrichment on Morphology, Structure and Oxidation Reactivity of Diesel Particulate, Applied Energy, 160, 442-455.

77. Pundir, B.P., Kumar, R., 2007. Combustion and Smoke Emission Studies on a Hydrogen Fuel Supplemented DI Diesel Engine. SAE Paper No. 2007-01-0055. 